\section{Discussion}

As in any hospital based study the patients in this report were selected because their eczema was either unusually severe or particularly refractory to treatment. Such patients are possibly more susceptible to herpes simplex infection than children with milder eczema. The control group was also imperfect in that the controls were not drawn from exactly the same geographical area as the-patients, they were not matched for social class, and some of them possibly had eczema.

The results showed that there was no significant difference between the overall herpes simplex seropositivity rates of the two groups, which were similar to those reported for Edinburgh children in $1967 .^{3}$ Our findings suggest that children with atopic eczema are no more likely to acquire herpes simplex infection than normal children. The severity of initial herpes simplex infections in some children with atopic eczema, combined with troublesome recurrent herpes infections in others, may give rise to a false clinical impression of a greater incidence of infection. Our results do not indicate what proportion of initial herpes simplex infections were subclinical, skin infection, or gingivostomatatis. We have been unable to produce serological evidence to confirm the claim that children with atopic eczema are more often infected with the virus than normal children, ${ }^{4}$ and the general claim that these children are more susceptible to viral infections ${ }^{5}$ requires further substantiation.

We thank Professor Garcia de Lomas, who did much of the laboratory work during a sabbatical visit to the Regional Virus Laboratory, and Professors $\mathbf{M}$ Longson and S Shuster for their helpful comments.

\section{References}

1 David TJ, Longson M. Herpes simplex infections in atopic eczema. Arch Dis Child 1985;60:338-43.

2 Pauls FP, Dowdle WR. A serologic study of herpesvirus hominis strains by microneutralization tests. $J$ Immunol 1967;98:941-7.

${ }^{3}$ Smith IW, Peutherer JF, MacCallum FO. The incidence of herpesvirus hominis antibody in the population. J Hyg (Lond) 1967;65:395-408.

4 Bonifazi E, Garofalo L, Pisani V, Meneghini CL. Role of some infectious agents in atopic dermatitis. Acta Derm Venereol [Suppl] Stockh 1985;114:98-100.

5 Strannegard O, Strannegard IL, Rystedt I. Viral infections in atopic dermatitis. Acta Derm Venereol [Suppl] Stockh $1985 ; 114: 121-4$.

Correspondence to Dr T J David, Department of Child Health, Booth Hall Children's Hospital, Charlestown Road, Blackley, Manchester M9 2AA, England.

Received 10 November 1986

\title{
Carbon monoxide concentrations in infant deaths
}

\section{S VARIEND AND A $\mathrm{R} W$ FORREST}

Department of Histopathology, Children's Hospital, and Department of Clinical Chemistry, Royal Hallamshire Hospital, Sheffield

for infant deaths in the United Kingdom seem to be

SUMMARY Carboxyhaemoglobin measured in 50 infant deaths showed no significant difference between home and hospital deaths nor between explained and unexplained deaths. Carbon monoxide toxicity is unlikely to have an important role in the pathogenesis of sudden infant deaths. The generally low carboxyhaemoglobin concentrations are probably due to endogenous production.

Carbon monoxide poisoning as a factor in the pathogenesis of sudden infant death has been questioned. ${ }^{1}$ Previous studies have been limited to North America, ${ }^{23}$ and carboxyhaemoglobin values unavailable.

\section{Patients and methods}

A consecutive series of 50 infants who died in South Yorkshire aged 1 week to 2 years was studied between January and November 1985. There were 12 hospital deaths with ascertainable cause (group A), 11 explained deaths at home (group B), and 27 unexplained deaths at home (group C). The boy to girl ratios in groups $\mathrm{A}, \mathrm{B}$, and $\mathrm{C}$ were $4: 8,4: 7$, and $17: 10$, respectively. In group $A$ the duration of admission to hospital varied from one day to one year. 
Carboxyhaemoglobin was measured using the spectrophotometric technique of Katsumata et al. $^{4}$ This method does not give a positive bias when analysing samples containing a high proportion of fetal haemoglobin. Values for 16 summer home deaths and 22 winter home deaths were compared to evaluate the possible effect of differences in seasonal domestic ventilation. The Mann-Whitney U test was the statistical method used.

\section{Results}

No association was found between carboxyhaemoglobin concentrations and postmortem interval nor between carboxyhaemoglobin concentrations and age. Mean carboxyhaemoglobin concentrations for groups $\mathrm{A}, \mathrm{B}$, and $\mathrm{C}$ were $2.9 \%$ (range $<0 \cdot 5-6 \cdot 7 \%$ ), $2.2 \%$ (range $<0.5-4 \%$ ), and $1.9 \%$ (range $<0.5$ $4.7 \%$, respectively. The difference in carboxyhaemoglobin values between explained deaths (groups A and B) and unexplained deaths (group C) was not significant. No significant difference was found in values between boys and girls (between all groups) nor for values obtained for summer and winter home deaths.

\section{Discussion}

The lack of significant difference in carboxyhaemoglobin values between the explained and unexplained deaths and between home and hospital deaths argues against carbon monoxide poisoning being a significant factor in the pathogenesis of sudden infant deaths.

Carbon monoxide is normally generated endogenously in the body from haemoglobin degradation; ${ }^{5}$ while its precise physiology is still unclear, diffusion through the lungs is a recognised mechanism of elimination. Consequently, pneumonia or other disease that interferes with pulmonary gas exchange may result in raised carboxyhaemoglobin concentrations. This may explain two relatively high values recorded for infants dying in hospital; one infant had cytomegalovirus pneumonia and the other had alveolar immaturity associated with prematurity.

Among infant deaths at home in Michigan (USA) carbon monoxide toxicity was found not to be a significant factor. ${ }^{2}$ On the other hand, carboxyhaemoglobin concentrations in excess of $5 \%$ were found in six of 141 infants aged less than 2 years in Chicago (USA). ${ }^{3}$ Two had considerably raised values (34 and $49 \%$ ) and were thought to have died from associated asphyxia. The values were much lower in the other four, and of these three had pneumonia.

Faulty combustion in domestic heating and cooking appliances is a potential source of exogenous carbon monoxide. If the carboxyhaemoglobin concentrations among the home deaths were the result of such emission lower values among infants dying in summer, when home ventilation would be likely to be more efficient, would be expected compared with winter concentrations. This was not found, suggesting that the carboxyhaemoglobin present was mainly derived from endogenously generated carbon monoxide.

This study was funded by the Foundation for the Study of Infant Deaths.

\section{References \\ ' Emery JL. Carbon monoxide and cot death. Lancet 1984;ii:1101 \\ 2 Smialck JE, Monforte JR. Toxicology and sudden infant death J Forensic Sci 1977;22:757-62. \\ ${ }^{3}$ Sturner WQ. Some perspectives in cot death. Journal of Forensic Medicine 1971:18:96-107. \\ ${ }^{4}$ Katsumata Y, Aoki M, Sato K, Suzuki O, Oya M, Yada S. A simple spectrophotometry for determination of carboxy- haemoglobin in blood. J Forensic Sci 1982:27:928-34. \\ 5 Coburn RF. Endogenous carboxyhacmoglobin production $N$ Engl J Med 1970;282:207-9.}

Correspondence to Dr S Variend, Department of Histopathology The Children's Hospital, Western Bank. Sheffield S10 2TH. England.

Received 27 October 1986 